Ayal A. Aizer, Harvard Radiation Oncology Program; Ellen P. McCarthy, Beth Israel Deaconess Medical Center; Mallika L. Mendu, Sophia Koo, Powell L. Graham, Neil E. Martin, and Paul L. Nguyen, Dana-Farber/Brigham and Women's Cancer Center; Tyler J. Wilhite, Harvard Medical School, Boston, MA; Ming-Hui Chen, University of Connecticut, Storrs, CT; Karen E. Hoffman, The University of Texas MD Anderson Cancer Center, Houston, TX; and $\operatorname{Jim} \mathrm{C}$. Hu, University of California at Los Angeles, Los Angeles, CA.

Published online ahead of print at www.jco.org on September 23, 2013.

Supported by a Heritage Medical Research Institute/Prostate Cancer Foundation Young Investigator Award, JCRT Foundation Grant, Fitz's Cancer Warriors, David and Cynthia Chapin, and a grant from an anonymous family foundation.

Authors' disclosures of potential conflicts of interest and author contributions are found at the end of this article.

Corresponding author: Paul L. Nguyen, MD, Brigham and Women's Hospital, Department of Radiation Oncology, 75 Francis St, Boston, MA 02115; e-mail: pnguyen@LROC.harvard.edu.

() 2013 by American Society of Clinical Oncology

0732-183X/13/3131w-3869w/\$20.00

DOI: 10.1200/JCO.2013.49.6489

\title{
Marital Status and Survival in Patients With Cancer
}

Ayal A. Aizer, Ming-Hui Chen, Ellen P. McCarthy, Mallika L. Mendu, Sophia Koo, Tyler J. Wilhite, Powell L. Graham, Toni K. Choueiri, Karen E. Hoffman, Neil E. Martin, Jim C. Hu, and Paul L. Nguyen

See accompanying editorial on page 3852

\section{$\begin{array}{llllllll}\text { A } & \text { B } & \text { S } & \text { T } & \text { R } & \text { A } & \text { C } & \text { T }\end{array}$}

\section{Purpose}

To examine the impact of marital status on stage at diagnosis, use of definitive therapy, and cancer-specific mortality among each of the 10 leading causes of cancer-related death in the United States.

\section{Methods}

We used the Surveillance, Epidemiology and End Results program to identify 1,260,898 patients diagnosed in 2004 through 2008 with lung, colorectal, breast, pancreatic, prostate, liver/intrahepatic bile duct, non-Hodgkin lymphoma, head/neck, ovarian, or esophageal cancer. We used multivariable logistic and Cox regression to analyze the 734,889 patients who had clinical and follow-up information available.

\section{Results}

Married patients were less likely to present with metastatic disease (adjusted odds ratio [OR], $0.83 ; 95 \% \mathrm{Cl}, 0.82$ to $0.84 ; P<.001$ ), more likely to receive definitive therapy (adjusted OR, 1.53; $95 \% \mathrm{Cl}, 1.51$ to $1.56 ; P<.001)$, and less likely to die as a result of their cancer after adjusting for demographics, stage, and treatment (adjusted hazard ratio, $0.80 ; 95 \% \mathrm{Cl}, 0.79$ to $0.81 ; P<.001$ ) than unmarried patients. These associations remained significant when each individual cancer was analyzed ( $P<.05$ for all end points for each malignancy). The benefit associated with marriage was greater in males than females for all outcome measures analyzed ( $P<.001$ in all cases). For prostate, breast, colorectal, esophageal, and head/neck cancers, the survival benefit associated with marriage was larger than the published survival benefit of chemotherapy.

\section{Conclusion}

Even after adjusting for known confounders, unmarried patients are at significantly higher risk of presentation with metastatic cancer, undertreatment, and death resulting from their cancer. This study highlights the potentially significant impact that social support can have on cancer detection, treatment, and survival.

\section{J Clin Oncol 31:3869-3876. (C) 2013 by American Society of Clinical Oncology}

\section{INTRODUCTION}

Fifty-one percent of Americans are married. ${ }^{1}$ Studies assessing the impact of marital status on diseasespecific survival among patients with cancer have yielded conflicting results, with protective, ${ }^{2-9}$ mixed, ${ }^{10-13}$ and nonsignificant ${ }^{14,15}$ effects identified by prior investigations, most of which involved a single malignancy. ${ }^{2,4-10,13}$ In addition, some $e^{3,10}$ but not all ${ }^{4,5}$ studies have identified a differential effect of marriage in men versus women, although a metaanalysis did not identify such effect modification. ${ }^{16}$ Ultimately, from prior studies, it is difficult to draw meaningful conclusions regarding the impact of marital status on survival among patients with cancer.

The presence of a consistent association between marital status and outcome across multiple cancers would support the notion that unmarried patients with any malignancy represent an at-risk population that might benefit from targeted, support-based interventions. Given that the National Institutes of Health/National Cancer Institute spends approximately $\$ 5$ billion per annum ${ }^{17}$ on cancer research focused mainly on biologic investigations, targeted social support interventions could prove to be a cost-effective method of improving survival among at-risk patients with cancer. We used the Surveillance, Epidemiology and End Results (SEER) database ${ }^{18}$ to study nearly 1 million contemporary patients and make generalizable conclusions regarding the impact of marital status on stage at presentation, use of definitive therapy, and disease-specific survival among each of the 10 leading causes of cancer-related death in the United States. 


\section{METHODS}

\section{Patient Population and Study Design}

We used the SEER database to identify 1,260,898 patients diagnosed in 2004 through 2008 with one of the 10 leading causes of cancer-related death (ie, lung, colorectal, breast, pancreatic, prostate, liver/intrahepatic bile duct, non-Hodgkin lymphoma, head/neck, ovarian, and esophageal cancer), each of which results in more than 15,000 deaths per annum in the United States. ${ }^{19}$ Sponsored by the National Cancer Institute, the SEER program collects and publishes cancer incidence, treatment, and survival data from populationbased cancer registries; the program captures approximately $97 \%$ of incident cancers, and the tumor registries cover approximately $26 \%$ of the United States population. ${ }^{18}$ The year 2004 was selected as the first year of the study given that several employed covariates were introduced in SEER in $2004 .{ }^{20}$ Patients were excluded if age at diagnosis was less than 18 years, a diagnosis of cancer was made at autopsy, a prior malignancy had been diagnosed, clinical information was incomplete, or if the cause of death was unknown, leaving 734,889 patients in the final cohort.

\section{Statistical Analysis}

Baseline patient characteristics were compared with the $t$ test or $\chi^{2}$ test, as appropriate. For each malignancy, multivariable logistic regression was used to determine the association of marital status on stage at diagnosis (metastatic $v$ nonmetastatic) after adjustment for demographic factors (age, sex, race, residence type [urban $v$ rural], education, and median household income). Race was classified as white, African American, Hispanic, or Asian American, as determined by SEER. ${ }^{18}$ Residence type, educational status (ie, percentage of adults $\geq 25$ years of age with a high school education), and median household income were determined at the county level by linkage to the 2003 US Department of Agriculture ruralurban continuum codes, ${ }^{21} 2000$ US Census, ${ }^{22}$ and 2004 small area income and poverty estimates from the US Census, respectively. ${ }^{23}$

After excluding patients with metastatic disease and those for whom the tumor stage, nodal stage, and therapy used was unknown (including all patients with non-Hodgkin lymphoma, given that information regarding chemotherapy, the primary management modality for such patients, is not available in SEER), 562,758 patients remained eligible for analysis of receipt of definitive therapy. Multivariable logistic regression was used to determine the association of marital status on use of appropriate definitive therapy after adjustment for demographic factors, tumor stage, and nodal stage. Tumor and nodal stage, delineating the local and regional extent of disease progression, respectively, were determined per the American Joint Committee on Cancer sixth edition. ${ }^{20}$ Appropriate definitive therapy was defined as surgery and/or radiation for prostate, lung, pancreatic, liver/ intrahepatic bile duct, esophageal, and head/neck cancer. In contrast, only surgery was considered to be the appropriate definitive therapy for breast, colorectal, and ovarian cancer.

For the outcome measure of cancer-specific mortality, Cox proportional hazards multivariable regression was used to assess the impact of marital status on cancer-specific mortality after adjustment for demographic factors, tumor stage, nodal stage, and use of definitive therapy. Among patients with breast cancer, only female patients were included in the analysis.

Marital status was classified as either married or unmarried and then also reanalyzed as married versus single, separated, divorced, or widowed. All logistic regression analyses were performed in a multilevel fashion to account for intracorrelations on the county level; for the Cox regression, a $\gamma$ frailty model $^{24}$ was used. The median follow-up among surviving patents for the cohort analyzed for cancer-specific mortality was 3.1 years (range, 0.1 to 5.9 years). All $P$ values are two-sided. The threshold of .05 was used to determine significance. Statistical analyses were performed by authors M.C. and A.A. using SAS version 9.3 (SAS Institute, Cary, NC). This study was approved by our institutional review board; informed consent was waived.

\section{RESULTS}

\section{Patient Characteristics}

Baseline patient characteristics are displayed in Table 1. Married patients were, on average, 2.5 years younger than unmarried patients and were more likely to be both male and white $(P<.001)$. In addition, patients who were married were more likely to be from counties that were rurally situated and that displayed higher income and education levels $(P<.001)$, although such differences were small in magnitude. Married patients were also less likely to present with advanced tumor and nodal stage than unmarried patients $(P<.001)$.

\section{Impact of Marital Status on Outcomes of Interest}

As displayed in Figure 1, after adjustment for demographics, married patients were less likely to present with metastatic disease than those who were unmarried (odds ratio [OR] 0.83; 95\% CI, 0.82 to $0.84 ; P<.001$ ), an association that remained significant when each cancer was evaluated individually (adjusted OR range for each cancer: 0.52 to $0.93 ; P<.05$ in all cases). After adjusting for demographics and tumor and nodal stage, married patients with nonmetastatic disease were more likely to undergo definitive surgical and/or radiotherapeutic management than unmarried patients (adjusted OR, 1.53; 95\% CI, 1.51 to $1.56 ; P<.001$ ), an effect that was significant in all cancers evaluated (adjusted OR range for each cancer, 1.42 to $1.76 ; P<.05$ in all cases).

On Cox regression for cancer-specific mortality, after adjusting for demographics, tumor and nodal stage, and use of definitive therapy, patients who were married were significantly less likely to die of their disease (adjusted hazard ratio [HR], 0.80; 95\% CI, 0.79 to 0.81 ; $P<.001$ ), an association that remained significant in all cancers evaluated (adjusted HR range, 0.67 to $0.88 ; P<.05$ in all cases). When the unmarried cohort was stratified among its respective components (never married, separated, divorced, and widowed), all subgroups of unmarried patients were more likely to present with metastatic disease, be undertreated, and die of their cancer than their married counterparts $(P<.001$ for all associations, see Table 2$)$. As shown in Table 3, among all patients evaluated, the effect of marriage on stage at presentation, use of definitive therapy, and cancer-specific mortality was greater for men than women $\left(P_{\text {interaction }}<.001\right.$ in all cases).

\section{DISCUSSION}

We found that unmarried patients, including those who are widowed, are at significantly greater risk of presentation with metastatic cancer, undertreatment, and death resulting from their cancer than patients who are married. The association between marital status and each of these outcomes was significant for every malignancy evaluated. After adjusting for demographics, stage, and treatment, marriage remained associated with a relative reduction in cancer death ranging from $12 \%$ to $33 \%$. In Table 4, for each solid malignancy, we compare the published HRs for the overall survival benefit of chemotherapy from landmark randomized trials, meta-analyses, and systematic reviews with the observed HRs for the survival benefit associated with marriage in our study. For five cancers studied (prostate, breast, colorectal, esophageal, and head/neck cancers), the survival benefit associated 


\begin{tabular}{|c|c|c|c|c|}
\hline \multirow[b]{2}{*}{ Characteristic* } & \multicolumn{2}{|c|}{$\begin{array}{c}\text { Unmarried } \\
(\mathrm{n}=275,728) \dagger\end{array}$} & \multicolumn{2}{|c|}{$\begin{array}{c}\text { Married } \\
(\mathrm{n}=459,161) \dagger \\
\end{array}$} \\
\hline & No. & $\%$ & No. & $\%$ \\
\hline \multicolumn{5}{|l|}{ Age, years } \\
\hline Mean & \multicolumn{2}{|l|}{66} & \multicolumn{2}{|l|}{63} \\
\hline SD & \multicolumn{2}{|l|}{14} & \multicolumn{2}{|l|}{12} \\
\hline \multicolumn{5}{|l|}{ Income, USD } \\
\hline Mean & \multicolumn{2}{|c|}{48,000} & \multicolumn{2}{|c|}{49,000} \\
\hline SD & \multicolumn{2}{|c|}{11,000} & \multicolumn{2}{|c|}{11,000} \\
\hline \multicolumn{5}{|l|}{$\begin{array}{l}\text { Percent that completed high } \\
\text { schoolf }\end{array}$} \\
\hline Mean & \multicolumn{2}{|l|}{79} & \multicolumn{2}{|l|}{80} \\
\hline SD & \multicolumn{2}{|l|}{8} & \multicolumn{2}{|l|}{8} \\
\hline \multicolumn{5}{|l|}{ Sex } \\
\hline Male & 109,321 & 40 & 272,225 & 59 \\
\hline Female & 166,407 & 60 & 186,936 & 41 \\
\hline \multicolumn{5}{|l|}{ Race } \\
\hline White & 190,320 & 69 & 344,883 & 75 \\
\hline Black & 46,048 & 17 & 38,330 & 8 \\
\hline Hispanic & 24,248 & 9 & 40,143 & 9 \\
\hline Asian & 13,670 & 5 & 33,945 & 7 \\
\hline Native American & 1,442 & 1 & 1,860 & 0 \\
\hline \multicolumn{5}{|l|}{ Residence $\neq$} \\
\hline Rural & 33,549 & 12 & 59,899 & 13 \\
\hline Urban & 242,179 & 88 & 399,262 & 87 \\
\hline \multicolumn{5}{|l|}{ Tumor stage§ } \\
\hline 1 & 95,716 & 37 & 192,535 & 45 \\
\hline 2 & 71,362 & 28 & 127,611 & 30 \\
\hline 3 & 45,795 & 18 & 62,018 & 14 \\
\hline 4 & 42,946 & 17 & 47,071 & 11 \\
\hline Not applicable & 19,909 & & 29,926 & \\
\hline Nodal stage§ & & & & \\
\hline 0 & 162,930 & 64 & 304,837 & 71 \\
\hline 1 & 43,651 & 17 & 62,948 & 15 \\
\hline 2 & 39,095 & 15 & 49,058 & 11 \\
\hline 3 & 10,143 & 4 & 12,392 & 3 \\
\hline Not applicable & 19,909 & & 29,926 & \\
\hline Metastatic disease at diagr & & & & \\
\hline No & 222,539 & 81 & 393,416 & 86 \\
\hline Yes & 53,189 & 19 & 65,745 & 14 \\
\hline Malignancy & & & & \\
\hline Prostate & 44,344 & 16 & 146,304 & 32 \\
\hline Breast & 75,689 & 27 & 107,907 & 24 \\
\hline Lung & 57,303 & 21 & 67,277 & 15 \\
\hline Colorectal & 44,526 & 16 & 61,483 & 13 \\
\hline Pancreatic & 7,795 & 3 & 11,430 & 2 \\
\hline Liver, IHBD & 5,884 & 2 & 8,185 & 2 \\
\hline Esophageal & 3,630 & 1 & 5,373 & 1 \\
\hline Ovarian & 7,096 & 3 & 8,426 & 2 \\
\hline Head/neck & 9,552 & 3 & 12,850 & 3 \\
\hline Non-Hodgkin lymphoma & 19,909 & 7 & 29,926 & 7 \\
\hline $\begin{array}{l}\text { Abbreviations: IHBD, intral } \\
\text { United States dollars. } \\
\text { *All } P \text { values comparing c } \\
\text { were }<.001 . \\
\text { +Percentages may not ado } \\
\text { †County-level data. } \\
\text { \$Patients with non-Hodgki } \\
\text { tumor or nodal stage and ar } \\
\text { \|In patients with non-Hodg }\end{array}$ & $\begin{array}{l}\text { oile duct; SL } \\
\text { stics of mar } \\
00 \text { because } \\
\text { oma could } n \\
\text { as not applic } \\
\text { homa, meta }\end{array}$ & $\begin{array}{l}\text { ed an } \\
\text { f rour } \\
\text { t be } \\
\text { ble. } \\
\text { tatic }\end{array}$ & $\begin{array}{l}\text { d deviation } \\
\text { unmarried } \\
\text { g. } \\
\text { ssified as h } \\
\text { ers to stage }\end{array}$ & $\begin{array}{l}\text { USD, } \\
\text { tients } \\
\text { ing a } \\
\text { J. }\end{array}$ \\
\hline
\end{tabular}

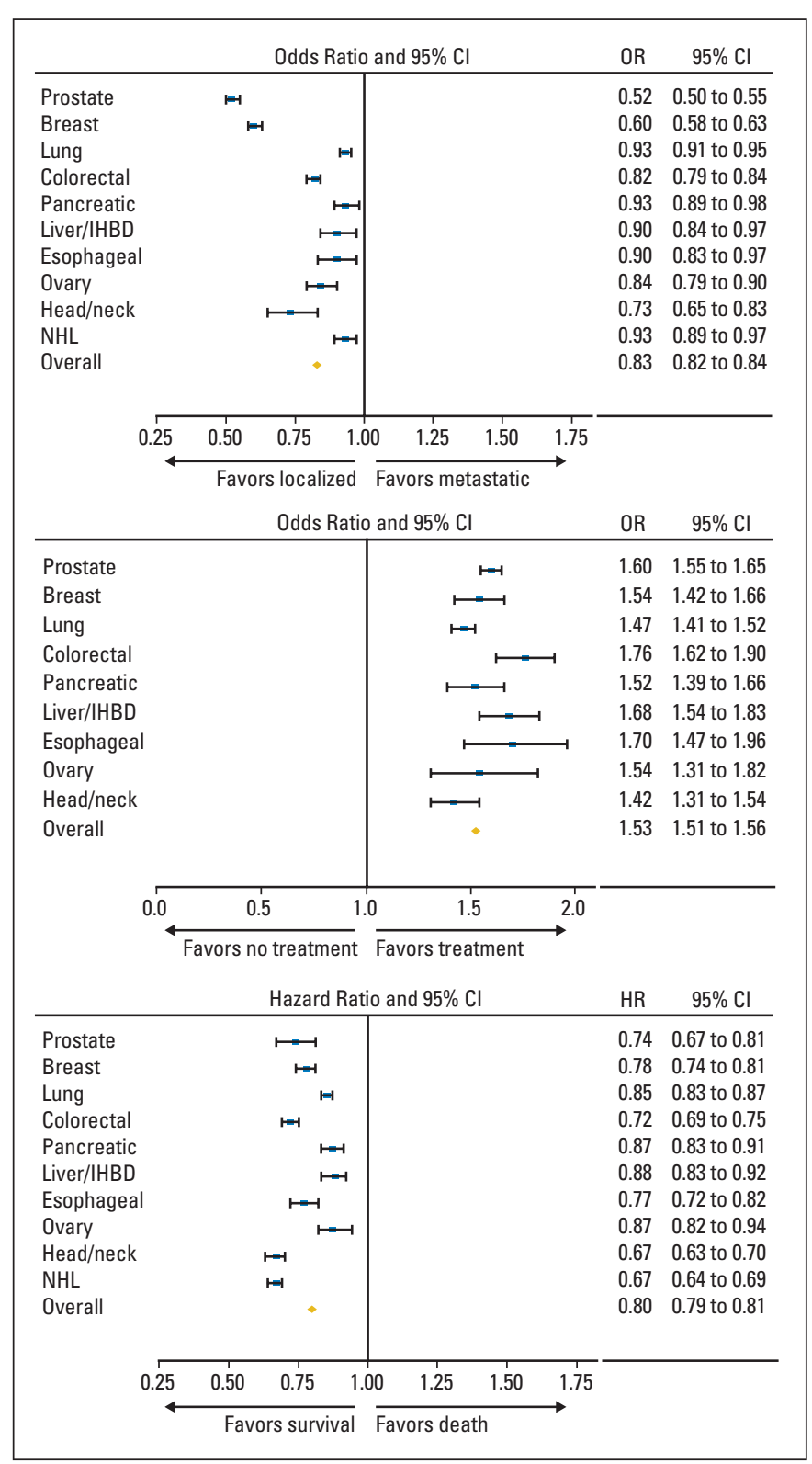

Fig 1. Forest plots depicting odds ratios and $95 \% \mathrm{Cls}$ for the $(\mathrm{A})$ association between marital status (married $v$ unmarried) and presentation with metastatic disease, (B) use of definitive therapy, and (C) cancer-specific mortality for each of the 10 cancers evaluated and among the entire cohort. Odds ratios for the outcome measure of presentation with metastatic disease are adjusted for the demographics of age, sex, race, income, education, and urban versus rural residence (exceptions: prostate, breast, and ovarian, no adjustment for sex; overall, also adjusted for primary site). Odds ratios for the outcome measure of use of definitive therapy are adjusted for demographics (age, sex, race, income, education, and urban $v$ rural residence), tumor stage, and nodal stage (exceptions: prostate, also adjusted for Gleason score and prostate-specific antigen [PSA], no adjustment for nodal stage or sex; breast and ovarian, no adjustment for sex; overall, excludes patients with non-Hodgkin lymphoma [NHL] and also adjusted for cancer stage and primary site but not tumor stage or nodal stage). Hazard ratios for the outcome measure of cancer-specific mortality are adjusted for demographics (age, sex, race, income, education, and urban $v$ rural residence), tumor stage, nodal stage, and whether definitive treatment was administered (exceptions: prostate, also adjusted for Gleason score and PSA, no adjustment for nodal stage or sex; breast and ovarian, not adjusted for sex; NHL, also adjusted for cancer stage and histology but not tumor stage, nodal stage, or use of definitive therapy; overall, excludes patients with NHL and also adjusted for cancer stage and primary site but not tumor stage or nodal stage). IHBD, intrahepatic bile duct. 
Table 2. Associations Between Specific Subgroups of the Unmarried Population and Outcomes of Presentation With Metastatic Disease, Use of Definitive Therapy, and CSM*

\begin{tabular}{|c|c|c|c|c|c|c|c|c|c|}
\hline \multirow[b]{2}{*}{ Population } & \multicolumn{3}{|c|}{ Metastatic Disease at Dx } & \multicolumn{3}{|c|}{ Definitive Treatment† } & \multicolumn{3}{|c|}{$\mathrm{CSM}+$} \\
\hline & OR $\neq$ & $95 \% \mathrm{Cl}$ & $P$ & OR§ & $95 \% \mathrm{Cl}$ & $P$ & $\mathrm{HR} \|$ & $95 \% \mathrm{Cl}$ & $P$ \\
\hline Married & Ref & & - & Ref & & - & Ref & & - \\
\hline Never married & 1.28 & 1.25 to 1.30 & $<.001$ & 0.57 & 0.55 to 0.58 & $<.001$ & 1.33 & 1.30 to 1.36 & $<.001$ \\
\hline Separated & 1.25 & 1.18 to 1.32 & $<.001$ & 0.67 & 0.61 to 0.73 & $<.001$ & 1.21 & 1.14 to 1.29 & $<.001$ \\
\hline Divorced & 1.21 & 1.18 to 1.23 & $<.001$ & 0.70 & 0.68 to 0.72 & $<.001$ & 1.24 & 1.21 to 1.27 & $<.001$ \\
\hline Widowed & 1.12 & 1.10 to 1.14 & $<.001$ & 0.70 & 0.68 to 0.72 & $<.001$ & 1.24 & 1.22 to 1.26 & $<.001$ \\
\hline
\end{tabular}

Abbreviations: CSM, cancer-specific mortality; Dx, diagnosis; HR, hazard ratio; OR, odds ratio.

*Includes patients from all 10 evaluated cancers for outcome of presentation with metastatic disease and all cancers except non-Hodgkin lymphoma for outcomes of selection of definitive therapy and cancer-specific mortality.

†Excludes patients with metastatic disease.

¥OR adjusted for demographics of age, sex, race, income, education, urban versus rural residence, and primary site.

$\S O R$ adjusted for demographics (age, sex, race, income, education, and urban $v$ rural residence), cancer stage, and primary site.

$\| H R$ adjusted for demographics (age, sex, race, income, education, and urban $v$ rural residence), cancer stage, primary site, and whether definitive surgical or radiotherapeutic treatment administered.

with marriage was larger than the published survival benefit of chemotherapy. The importance of this study is that it highlights the consistent and substantial impact that features of marriage, particularly social support, can have on cancer detection, treatment, and survival. It raises the possibility that investments in targeted social support interventions aimed at vulnerable populations, such as unmarried patients, could significantly improve the likelihood of achieving cure. Pending further investigations, including cost-benefit analyses, such interventions may prove to be a cost-effective method of improving outcomes among unmarried patients with cancer.

The association between married status and earlier stage at presentation identified in this study may reflect better access to care for married versus unmarried patients, ${ }^{34}$ although even in nations with universal access to free care, such as Denmark, sociodemographic factors affect outcome in a multitude of health conditions. ${ }^{35-37}$ Marital status may also impact stage at diagnosis for patients with cancer given possible encouragement by spouses to seek medical attention for worrisome symptoms. Spouses also may encourage patients to undergo definitive versus expectant management, ${ }^{38}$ potentially accounting for the discrepancies in definitive treatment we identified. There are many explanations for the vital question of why marriage is associated with improved cancer-specific survival after adjustment for demographics, stage, and treatment, but the most likely reason is that married patients have better adherence with prescribed treatments than unmarried patients. ${ }^{39}$ Impaired adherence has been associated with poorer outcomes in patients with cancer. For example, in head/neck cancers, missed or delayed radiation treatments are associated with increased rates of locoregional recurrence and death. ${ }^{40}$ Interestingly, in our study, married patients with head/neck cancers displayed the greatest relative reduction in cancer death $(33 \%)$. Investigations relating adherence to outcome in patients with breast, hematologic, and other cancers have yielded similar results. ${ }^{41-43}$

The benefits of marriage on all of the outcomes evaluated in this study have additional potential underlying etiologies. Psychologically, the diagnosis of cancer may result in more distress than other diagnoses. ${ }^{44}$ Patients who are married display less distress, depression, and anxiety than their unmarried counterparts after a diagnosis of cancer, as a partner can share the emotional burden and provide appropriate social support. ${ }^{45}$ Depression may, in part, be a mediator of the associ- ation between marital status and adherence to medical recommendations. DiMatteo et $\mathrm{al}^{46}$ demonstrated a strong relationship between depression and nonadherence, and married patients display lower risk of major depression. ${ }^{47}$ Other studies have shown that women with depression who are diagnosed with breast cancer undergo definitive treatment less often and display poorer survival. ${ }^{48}$ Physicians should consider screening for depression among unmarried patients with cancer and refer patients to mental health specialists if symptoms are identified. In addition, physicians should consider closer observation of unmarried patients with cancer to maximize adherence. Given that patients who lack emotional support mechanisms do poorly after diagnosis with numerous health-related conditions, ${ }^{49}$ the importance of adequate support cannot be understated.

Physiologically, select studies have linked marriage to improvements in cardiovascular, endocrine, and immune function, although marriage quality may be a determinant of the magnitude and presence of this effect. ${ }^{50,51}$ Cortisol levels seem to be lower in patients with cancer who have adequate support networks, and diurnal cortisol patterns have been linked with natural-killer cell count and survival in patients with cancer, ${ }^{52,53}$ potentially providing a physiologic basis for the psychologically based data described previously. ${ }^{54}$ Further investigations on this subject are warranted.

If the benefits of marriage on survival are mediated through improved support, then the most effective way to combat the increased risks associated with unmarried status in patients with cancer would be to aggressively promote support mechanisms. Some of the available literature supports such an approach. In patients with heart failure, provision of informational, emotional, and affectionate support were associated with minimization of functional decline $e^{55}$ and improved health-related quality of life. ${ }^{56}$ Among patients with metastatic breast cancer, a randomized controlled trial conducted by Spiegel et al revealed that a psychosocial support-based intervention was associated with a near doubling of overall survival. ${ }^{57}$ It is important to note, however, that a randomized, controlled trial published by Goodwin et al, in which patients with metastatic breast cancer were randomly assigned in a 2:1 fashion to either receive weekly supportiveexpressive group therapy or no such intervention, did not identify survival differences between the two arms, even though women in the 
Table 3. Assessment of Effect Modification Between Marital Status and Sex for the Outcomes of Presentation With Metastatic Disease, Employment of Definitive Therapy, and CSM

\begin{tabular}{|c|c|c|c|c|c|c|c|c|c|c|}
\hline \multirow[b]{2}{*}{$\begin{array}{l}\text { Cancer and } \\
\text { Sex }\end{array}$} & \multicolumn{3}{|c|}{ Metastatic Disease at Dx } & \multirow[b]{2}{*}{$\begin{array}{c}\text { Definition of } \\
\text { Definitive Treatment }\end{array}$} & \multicolumn{3}{|c|}{ Definitive Treatment* } & \multicolumn{3}{|c|}{$\mathrm{CSM}^{*}$} \\
\hline & $\begin{array}{l}\text { OR for } \\
\text { Marriaget }\end{array}$ & $95 \% \mathrm{Cl}$ & $P \ddagger$ & & $\begin{array}{c}\text { OR for } \\
\text { Marriage }\end{array}$ & $95 \% \mathrm{Cl}$ & $P \ddagger$ & $\begin{array}{c}\text { HR for } \\
\text { Marriage\| }\end{array}$ & $95 \% \mathrm{Cl}$ & $P \ddagger$ \\
\hline \multicolumn{11}{|l|}{ Lung } \\
\hline Interaction & & & .02 & S, RT & & & $<.001$ & & & .87 \\
\hline Male & 0.91 & 0.88 to 0.93 & $<.001$ & $\mathrm{~S}, \mathrm{RT}$ & 1.57 & 1.49 to 1.65 & $<.001$ & 0.85 & 0.83 to 0.88 & $<.001$ \\
\hline Female & 0.95 & 0.93 to 0.98 & .003 & $\mathrm{~S}, \mathrm{RT}$ & 1.36 & 1.28 to 1.44 & $<.001$ & 0.85 & 0.82 to 0.88 & $<.001$ \\
\hline \multicolumn{11}{|l|}{ Colorectal } \\
\hline Interaction & & & $<.001$ & S & & & .003 & & & $<.001$ \\
\hline Male & 0.75 & 0.72 to 0.78 & $<.001$ & S & 1.95 & 1.76 to 2.17 & $<.001$ & 0.66 & 0.63 to 0.70 & $<.001$ \\
\hline Female & 0.89 & 0.86 to 0.93 & $<.001$ & S & 1.54 & 1.37 to 1.73 & $<.001$ & 0.79 & 0.75 to 0.83 & $<.001$ \\
\hline \multicolumn{11}{|l|}{ Pancreatic } \\
\hline Interaction & & & .46 & $\mathrm{~S}, \mathrm{RT}$ & & & .93 & & & .02 \\
\hline Male & 0.91 & 0.85 to 0.98 & .01 & S, RT & 1.51 & 1.32 to 1.73 & $<.001$ & 0.82 & 0.76 to 0.87 & $<.001$ \\
\hline Female & 0.95 & 0.89 to 1.01 & .12 & $S, R T$ & 1.52 & 1.35 to 1.71 & $<.001$ & 0.91 & 0.85 to 0.96 & .002 \\
\hline \multicolumn{11}{|l|}{ Liver, IHBD } \\
\hline Interaction & & & .61 & $\mathrm{~S}, \mathrm{RT}$ & & & .25 & & & .35 \\
\hline Male & 0.89 & 0.82 to 0.98 & .01 & $\mathrm{~S}, \mathrm{RT}$ & 1.73 & 1.57 to 1.92 & $<.001$ & 0.86 & 0.81 to 0.92 & $<.001$ \\
\hline Female & 0.93 & 0.81 to 1.08 & .36 & $\mathrm{~S}, \mathrm{RT}$ & 1.56 & 1.34 to 1.82 & $<.001$ & 0.91 & 0.83 to 1.00 & .05 \\
\hline \multicolumn{11}{|l|}{ Esophagus } \\
\hline Interaction & & & .48 & $S, R T$ & & & .08 & & & .75 \\
\hline Male & 0.89 & 0.81 to 0.97 & .009 & S, RT & 1.82 & 1.55 to 2.14 & $<.001$ & 0.76 & 0.71 to 0.83 & $<.001$ \\
\hline Female & 0.95 & 0.79 to 1.15 & .61 & S, RT & 1.34 & 1.00 to 1.80 & .05 & 0.78 & 0.68 to 0.91 & .001 \\
\hline \multicolumn{11}{|l|}{ Head/neck } \\
\hline Interaction & & & .15 & $\mathrm{~S}, \mathrm{RT}$ & & & .80 & & & .007 \\
\hline Male & 0.70 & 0.62 to 0.80 & $<.001$ & $\mathrm{~S}, \mathrm{RT}$ & 1.42 & 1.29 to 1.57 & $<.001$ & 0.64 & 0.60 to 0.68 & $<.001$ \\
\hline Female & 0.86 & 0.67 to 1.10 & .24 & $\mathrm{~S}, \mathrm{RT}$ & 1.39 & 1.21 to 1.61 & $<.001$ & 0.75 & 0.68 to 0.84 & $<.001$ \\
\hline \multicolumn{11}{|l|}{$\mathrm{NHL}$} \\
\hline Interaction & & & .28 & & & & - & & & .26 \\
\hline Male & 0.91 & 0.86 to 0.96 & $<.001$ & - & - & & - & 0.66 & 0.63 to 0.69 & $<.001$ \\
\hline Female & 0.95 & 0.90 to 1.00 & .07 & - & - & & - & 0.68 & 0.65 to 0.72 & $<.001$ \\
\hline \multicolumn{11}{|l|}{ Overall } \\
\hline Interaction & & & $<.001$ & Per site & & & $<.001$ & & & $<.001$ \\
\hline Male & 0.87 & 0.85 to 0.89 & $<.001$ & Per site & 1.60 & 1.55 to 1.66 & $<.001$ & 0.77 & 0.76 to 0.79 & $<.001$ \\
\hline Female & 0.94 & 0.92 to 0.96 & $<.001$ & Per site & 1.43 & 1.37 to 1.49 & $<.001$ & 0.84 & 0.82 to 0.86 & $<.001$ \\
\hline
\end{tabular}

Abbreviations: Dx, diagnosis; CSM, cancer-specific mortality; HR, hazard ratio; IHBD, intrahepatic bile duct; NHL, non-Hodgkin lymphoma; OR, odds ratio; RT, radiation; S, surgery.

*Excludes patients with metastatic disease.

tOR for marriage adjusted for demographics of age, race, income, education, and urban versus rural residence (exception: overall, also adjusted for primary site). $\ddagger P$ values for interaction terms test whether there is a significant difference in the OR (or HR) between male and female patients.

$\S O R$ for marriage adjusted for demographic factors (age, race, income, education, and urban $v$ rural residence), tumor stage, and nodal stage (exceptions: prostate, also adjusted for Gleason score and prostate-specific antigen, no adjustment for nodal stage; overall, also adjusted for cancer stage and primary site but not tumor stage or nodal stage).

|HR for marriage adjusted for demographic factors (age, race, income, education, and urban $v$ rural residence), tumor stage, nodal stage, and whether definitive treatment administered (exceptions: prostate, also adjusted for Gleason score and prostate-specific antigen, no adjustment for nodal stage; NHL, also adjusted for cancer stage and histology but not tumor stage, nodal stage, or use of definitive therapy; overall, also adjusted for cancer stage and primary site but not tumor stage or nodal stage).

IIncludes data from the seven preceding cancers for outcome of presentation with metastatic disease and all preceding cancers except NHL for outcomes of selection of definitive therapy and cancer-specific mortality.

intervention arm experienced greater improvement in both psychological symptoms and pain control. ${ }^{59}$ In addition, in a second randomized study by Spiegel et $\mathrm{al}^{59}$ no significant benefit of supportive-expressive group therapy was noted on overall survival. Subsequent reviews of the literature have indicated that group psychological therapies do not confer survival benefits to women with metastatic breast cancer. ${ }^{60-62}$ More recently, a randomized trial of patients with metastatic non-small-cell lung cancer showed that early implementation of supportive measures/palliative care along with standard oncologic care improved the median survival of patients relative to standard oncologic care alone. ${ }^{63}$ Patients in the intervention arm underwent aggressive symptom management (including assessment/ management of depression and anxiety), received assistance with decision making, and were provided with coping strategies. This study suggests that provision of these support mechanisms to unmarried patients with serious medical conditions including cancer might significantly reduce mortality and help close the "survival gap" identified in the current study.

Prior investigations examined the impact of marriage on patients with largely a single malignancy. ${ }^{2,4-10,13}$ Two large, population-based studies in the United States, however, have previously evaluated the impact of marriage on outcomes in patients with numerous 


\begin{tabular}{|c|c|c|c|c|c|c|}
\hline Cancer & $\begin{array}{c}\text { Type of } \\
\text { Chemotherapy } \\
\text { Study }\end{array}$ & $\begin{array}{l}\text { Population Evaluated in } \\
\text { Chemotherapy Study }\end{array}$ & Chemotherapy & Reference & $\begin{array}{c}\text { HR for } \\
\text { Chemotherapy }\end{array}$ & $\begin{array}{l}\mathrm{HR}^{*} \text { for Marriage } \\
\text { in Present Study }\end{array}$ \\
\hline Prostate & Randomized trial ${ }^{25}$ & $\begin{array}{l}\text { Metastatic, hormone-resistant } \\
\text { prostate cancer }\end{array}$ & $\begin{array}{l}\text { Docetaxel every } 3 \\
\text { weeks }\end{array}$ & Mitoxantrone & 0.79 & 0.74 \\
\hline Breast & Meta-analysis ${ }^{26}$ & Early breast cancer & Anthracycline-based & No chemotherapy & 0.84 & 0.78 \\
\hline Lung & Systematic review 27 & $\begin{array}{l}\text { Stage I-III non-small-cell lung } \\
\text { cancer }\end{array}$ & Any & No chemotherapy & 0.71 & 0.85 \\
\hline Colorectal & Randomized trial ${ }^{28}$ & $\begin{array}{l}\text { T3-T4, resectable rectal } \\
\text { cancer }\end{array}$ & $\begin{array}{l}\text { Adjuvant fluorouracil } \\
\text { and leucovorin }\end{array}$ & No adjuvant chemotherapy & 0.85 & 0.72 \\
\hline Pancreatic & Randomized trial ${ }^{29}$ & Resectable pancreatic cancer & Fluorouracil & No chemotherapy & 0.71 & 0.87 \\
\hline Liver, IHBD & Randomized trial ${ }^{30}$ & $\begin{array}{l}\text { Advanced hepatocellular } \\
\text { carcinoma }\end{array}$ & Sorafenib & No chemotherapy & 0.69 & 0.88 \\
\hline Esophageal & Meta-analysis ${ }^{31}$ & $\begin{array}{l}\text { Resectable esophageal } \\
\text { cancer }\end{array}$ & Any & No chemotherapy & 0.87 & 0.77 \\
\hline Ovarian & Systematic review ${ }^{32}$ & $\begin{array}{l}\text { Early-stage epithelial ovarian } \\
\text { cancer }\end{array}$ & Any & No chemotherapy & 0.74 & 0.87 \\
\hline Head/neck & Meta-analysis ${ }^{33}$ & $\begin{array}{l}\text { Nonmetastatic head and neck } \\
\text { cancer }\end{array}$ & Any & No chemotherapy & 0.87 & 0.67 \\
\hline
\end{tabular}

cancers. $^{11,12}$ In a study by Goodwin et al, ${ }^{11}$ which included 25,706 patients from New Mexico diagnosed with cancer between 1969 and 1982, unmarried patients with certain cancers displayed poorer overall survival than patients who were married. However, for the majority of the individual cancers evaluated, the association with marriage did not achieve statistical significance, limiting the conclusions that can be drawn from the study. In addition, given that all patients were from New Mexico, the results may not be generalizable to all Americans. In a later study by Lai et $\mathrm{al}^{12}{ }^{12}$ the association between marital status and overall survival was assessed for 261,070 patients with cancer. For some but not all cancers, the effect of marital status proved significant. Notably, in both studies, the primary outcome was overall survival, as opposed to cancer-specific survival, increasing the likelihood that an unidentified confounding variable was the driver of the results. Our study, which uses cancer-specific survival as the primary end point, minimizes this possibility. The greater power of our study to detect significant differences in outcome among married versus unmarried patients likely allowed us to find significant associations between marital status and stage at presentation, use of definitive therapy, and cancer-specific mortality for every cancer evaluated. Our study shows a clear and consistent protective effect of marriage among patients harboring one of the 10 most clinically significant malignancies affecting Americans. In addition, given that SEER now represents $26 \%$ of the United States population, our results, based on nearly 1 million contemporary patients, may be more generalizable than those of prior investigations.

Interestingly, the impact of marriage on both stage at presentation, use of definitive therapy, and cancer-specific mortality seemed to be greater in men than in women $\left(P_{\text {interaction }}<.001\right.$ in all cases $)$. In addition, among individual cancers, when a significant interaction was present between sex and marital status for these outcome measures, male patients benefitted more from marriage than did female patients. The exact reasons for this will need to be explored further, but it could, for example, reflect that unmarried women receive greater social support from their relatives (eg, their own children), friends, or the community than unmarried men.
Potential limitations of our study should be considered. First, our results may not apply to cancers not evaluated in this study. Second, data related to chemotherapy are not available in SEER. Third, although all patients eligible for the analysis of appropriate definitive therapy had localized disease for which surgery and/or radiation offered the only option for cure, it may have been appropriate to withhold such therapy in select cases (eg, impaired performance status, low-risk prostate cancer). Fourth, it is possible that some patients cohabitated with a partner in the absence of marriage, although the percentage of Americans engaged in such a living arrangement was likely small. ${ }^{64}$ Moreover, such patients would be categorized as unmarried by SEER yet would be expected to display better outcomes than the unmarried population at large, thereby biasing our results toward the null. Data from the 2010 US Census indicate that approximately 90 million unmarried Americans more than 15 years old live "with other persons," whereas only approximately 30 million live alone. ${ }^{65}$ Although SEER does not record such information (including cohabitation with adult children), our data suggest that living with someone other than a spouse (eg, a roommate, child) does not confer the same protective effect on cancer outcome as marriage. Fifth, data relating to past/present smoking and alcohol use, factors linked to survival among patients with cancer, ${ }^{66-70}$ are not available in SEER, and some studies have suggested that unmarried patients may be at greater risk of such habits. ${ }^{71,72}$ Physicians should inquire about smoking and alcohol use, particularly in unmarried patients. Lastly, it is possible that unmarried patients are innately different from married patients in ways that cannot be accounted for by our multivariable analysis and that the associations between marital status and outcome identified in this study reflect the influence of an unmeasured confounder. This possibility is mitigated, however, by the fact that widowed patients also displayed poorer outcomes than patients who were married, suggesting that the lack of social support, and not the presence of an unmeasured confounder, is the true driver of the results presented in this study. However, given these limitations, caution should be exerted before assuming that improved social support would significantly improve outcomes in unmarried patients. 
Despite these potential limitations, our study indicates that unmarried patients are at greater risk of presentation with metastatic disease, undertreatment, and cancer-specific mortality. Physicians caring for unmarried patients with cancer should be aware of the poorer outcomes seen in this population, and health care systems should consider investing in highly targeted social support services and interventions that may help to reduce the significant survival differences between married and unmarried patients with cancer.

\section{AUTHORS' DISCLOSURES OF POTENTIAL CONFLICTS} OF INTEREST

Although all authors completed the disclosure declaration, the following author(s) and/or an author's immediate family member(s) indicated a financial or other interest that is relevant to the subject matter under consideration in this article. Certain relationships marked with a " $U$ " are those for which no compensation was received; those relationships marked with a " $C$ " were compensated. For a detailed description of the disclosure categories, or for more information about ASCO's conflict of interest policy, please refer to the Author Disclosure Declaration and the Disclosures of Potential Conflicts of Interest section in Information for Contributors. Employment or Leadership Position: None Consultant or Advisory Role: Paul L. Nguyen, Ferring Pharmaceuticals (C), Medivation (C) Stock Ownership: None Honoraria: None Research Funding: Paul L. Nguyen, Varian Medical Systems Expert Testimony: None Patents: None Other Remuneration: None

\section{AUTHOR CONTRIBUTIONS}

Conception and design: All authors

Administrative support: Ellen P. McCarthy, Powell L. Graham, Paul L. Nguyen

Collection and assembly of data: Ayal A. Aizer, Ellen P. McCarthy, Powell L. Graham, Paul L. Nguyen

Data analysis and interpretation: Ayal A. Aizer, Ming-Hui Chen, Ellen P. McCarthy, Toni K. Choueiri, Karen E. Hoffman, Neil E. Martin, Jim C. Hu, Paul L. Nguyen

Manuscript writing: All authors

Final approval of manuscript: All authors

\section{REFERENCES}

1. Pew Research Center: Social and demographic trends. http://www.pewsocialtrends.org

2. Fosså SD, Cvancarova $M$, Chen $L$, et al: Adverse prognostic factors for testicular cancerspecific survival: A population-based study of 27,948 patients. J Clin Oncol 29:963-970, 2011

3. Rendall MS, Weden MM, Favreault MM, et al: The protective effect of marriage for survival: A review and update. Demography 48:481-506, 2011

4. Sammon JD, Morgan M, Djahangirian O, et al: Marital status: A gender-independent risk factor for poorer survival after radical cystectomy. BJU Int 110:1301-1309, 2012

5. Wang L, Wilson SE, Stewart DB, et al: Marital status and colon cancer outcomes in US Surveillance, Epidemiology and End Results registries: Does marriage affect cancer survival by gender and stage? Cancer Epidemiol 35:417-422, 2011

6. Mahdi H, Kumar S, Munkarah AR, et al: Prognostic impact of marital status on survival of women with epithelial ovarian cancer. Psychooncology 22: 83-88, 2013

7. Baine M, Sahak F, Lin C, et al: Marital status and survival in pancreatic cancer patients: A SEER based analysis. PLoS One 6:e21052, 2011

8. Krongrad A, Lai $H$, Burke MA, et al: Marriage and mortality in prostate cancer. J Urol 156:16961700, 1996

9. Osborne C, Ostir GV, Du X, et al: The influence of marital status on the stage at diagnosis, treatment, and survival of older women with breast cancer. Breast Cancer Res Treat 93:41-47, 2005

10. Nelles JL, Joseph SA, Konety BR: The impact of marriage on bladder cancer mortality. Urol Oncol 27:263-267, 2009

11. Goodwin JS, Hunt WC, Key CR, et al: The effect of marital status on stage, treatment, and survival of cancer patients. JAMA 258:3125-3130, 1987

12. Lai $H$, Lai $S$, Krongrad $A$, et al: The effect of marital status on survival in late-stage cancer patients: An analysis based on surveillance, epidemiology, and end results (SEER) data, in the United States. Int J Behav Med 6:150-176, 1999
13. Reyes Ortiz CA, Freeman JL, Kuo YF, et al: The influence of marital status on stage at diagnosis and survival of older persons with melanoma. J Gerontol A Biol Sci Med Sci 62:892-898, 2007

14. Greenberg ER, Chute CG, Stukel $T$, et al: Social and economic factors in the choice of lung cancer treatment: A population-based study in two rural states. N Engl J Med 318:612-617, 1988

15. Jatoi A, Novotny $P$, Cassivi $S$, et al: Does marital status impact survival and quality of life in patients with non-small cell lung cancer? Observations from the mayo clinic lung cancer cohort. Oncologist 12:1456-1463, 2007

16. Manzoli L, Villari $P, M$ Pirone $G$, et al: Marital status and mortality in the elderly: A systematic review and meta-analysis. Soc Sci Med 64:77-94, 2007

17. National Cancer Institute: Cancer research funding. http://www.cancer.gov/cancertopics/factsheet/NCl/ research-funding

18. Surveillance, Epidemiology, and End Results (SEER) Program: Research Data (1973-2009), National Cancer Institute, DCCPS, Surveillance Research Program, Surveillance Systems Branch, released April 2012, based on the November 2011 submission. www.seer.cancer.gov

19. American Cancer Society: Cancer Facts \& Figures 2012. www.cancer.gov

20. American Joint Committee on Cancer: AJCC Staging Manual (ed 6). http://www.cancerstaging.org

21. United States Department of Agriculture: RuralUrban Continuum Codes. http://www.ers.usda.gov/dataproducts/rural-urban-continuum-codes.aspx

22. United States Census Bureau: Census 2000 Gateway. http://www.census.gov/main/www/cen2000.html

23. United States Census: Small Area Income and Poverty Estimates. http://www.census.gov/did/www/ saipe/data/statecounty/data/2004.html

24. Therneau TM, Grambsch PM: Modeling Survival Data: Extending the Cox Model. New York, NY, Springer-Verlag, 2000, pp 231-260

25. Berthold DR, Pond GR, Soban F, et al: Docetaxel plus prednisone or mitoxantrone plus prednisone for advanced prostate cancer: Updated survival in the TAX 327 study. J Clin Oncol 26:242245, 2008

26. Early Breast Cancer Trialists' Collaborative Group (EBCTCG), Peto R, Davies C, et al: Compari- sons between different polychemotherapy regimens for early breast cancer: Meta-analyses of long-term outcome among 100,000 women in 123 randomised trials. Lancet 379:432-444, 2012

27. O'Rourke N, Roque IFM, Farre Bernado $N$, et al: Concurrent chemoradiotherapy in non-small cell lung cancer. Cochrane Database Syst Rev 6:CD002140, 2010

28. Bosset JF, Collette L, Calais G, et al: Chemotherapy with preoperative radiotherapy in rectal cancer. N Engl J Med 355:1114-1123, 2006

29. Neoptolemos JP, Stocken DD, Friess H, et al: A randomized trial of chemoradiotherapy and chemotherapy after resection of pancreatic cancer. $\mathrm{N}$ Engl J Med 350:1200-1210, 2004

30. Llovet JM, Ricci S, Mazzaferro V, et al: Sorafenib in advanced hepatocellular carcinoma. N Engl J Med 359:378-390, 2008

31. Sjoquist KM, Burmeister BH, Smithers BM, et al: Survival after neoadjuvant chemotherapy or chemoradiotherapy for resectable oesophageal carcinoma: An updated meta-analysis. Lancet Oncol 12: 681-692, 2011

32. Winter-Roach BA, Kitchener HC, Lawrie TA: Adjuvant (post-surgery) chemotherapy for early stage epithelial ovarian cancer. Cochrane Database Syst Rev 3:CD004706, 2012

33. Blanchard $P$, Baujat B, Holostenco V, et al: Meta-analysis of chemotherapy in head and neck cancer (MACH-NC): A comprehensive analysis by tumour site. Radiother Oncol 100:33-40, 2011

34. Ayanian JZ, Kohler BA, Abe T, et al: The relation between health insurance coverage and clinical outcomes among women with breast cancer. N Engl J Med 329:326-331, 1993

35. Vallgårda S: Addressing individual behaviours and living conditions: Four Nordic public health policies. Scand J Public Health 39:6-10, 2011

36. Arntzen A, Nybo Andersen AM: Social determinants for infant mortality in the Nordic countries, 1980-2001. Scand J Public Health 32:381-389, 2004

37. Jakobsen L, Niemann T, Thorsgaard N, et al: Dimensions of socioeconomic status and clinical outcome after primary percutaneous coronary intervention. Circ Cardiovasc Interv 5:641-648, 2012

38. Aizer AA, Paly JJ, Zietman AL, et al: Multidisciplinary care and pursuit of active surveillance in 
low-risk prostate cancer. J Clin Oncol 30:3071-3076, 2012

39. Cohen SD, Sharma T, Acquaviva $K$, et al: Social support and chronic kidney disease: An update. Adv Chronic Kidney Dis 14:335-344, 2007

40. Pajak TF, Laramore GE, Marcial VA, et al: Elapsed treatment days-a critical item for radiotherapy quality control review in head and neck trials: RTOG report. Int J Radiat Oncol Biol Phys 20:13-20, 1991

41. McCowan C, Shearer J, Donnan PT, et al: Cohort study examining tamoxifen adherence and its relationship to mortality in women with breast cancer. Br J Cancer 99:1763-1768, 2008

42. Li BD, Brown WA, Ampil FL, et al: Patient compliance is critical for equivalent clinical outcomes for breast cancer treated by breast-conservation therapy. Ann Surg 231:883-889, 2000

43. Richardson JL, Shelton DR, Krailo M, et al: The effect of compliance with treatment on survival among patients with hematologic malignancies. J Clin Oncol 8:356-364, 1990

44. Kaiser NC, Hartoonian N, Owen JE: Toward a cancer-specific model of psychological distress: Population data from the 2003-2005 National Health Interview Surveys. J Cancer Surviv 4:291-302, 2010

45. Goldzweig G, Andritsch E, Hubert A, et al: Psychological distress among male patients and male spouses: What do oncologists need to know? Ann Oncol 21:877-883, 2010

46. DiMatteo MR, Lepper HS, Croghan TW: Depression is a risk factor for noncompliance with medical treatment: Meta-analysis of the effects of anxiety and depression on patient adherence. Arch Intern Med 160:2101-2107, 2000

47. Weissman MM, Bland RC, Canino GJ, et al: Cross-national epidemiology of major depression and bipolar disorder. JAMA 276:293-299, 1996

48. Goodwin JS, Zhang DD, Ostir GV: Effect of depression on diagnosis, treatment, and survival of older women with breast cancer. J Am Geriatr Soc 52:106-111, 2004

49. Krumholz HM, Butler J, Miller J, et al: Prognostic importance of emotional support for elderly patients hospitalized with heart failure. Circulation 97:958-964, 1998

50. Gallo LC, Troxel WM, Matthews KA, et al: Marital status and quality in middle-aged women: Associations with levels and trajectories of cardiovascular risk factors. Health Psychol 22:453-463, 2003

51. Herberman RB, Ortaldo JR: Natural killer cells: Their roles in defenses against disease. Science 214:24-30, 1981

52. Sephton SE, Lush E, Dedert EA, et al: Diurnal cortisol rhythm as a predictor of lung cancer survival. Brain Behav Immun 30:S163-S170, 2013 (suppl)

53. Sephton SE, Sapolsky RM, Kraemer HC, et al: Diurnal cortisol rhythm as a predictor of breast cancer survival. J Natl Cancer Inst 92:994-1000, 2000

54. Turner-Cobb JM, Sephton SE, Koopman C, et al: Social support and salivary cortisol in women with metastatic breast cancer. Psychosom Med 62:337-345, 2000

55. Berard DM, Vandenkerkhof EG, Harrison M, et al: Gender differences in the influence of social support on one-year changes in functional status in older patients with heart failure. Cardiol Res Pract 2012:616372, 2012

56. Bennett SJ, Perkins SM, Lane KA, et al: Social support and health-related quality of life in chronic heart failure patients. Qual Life Res 10:671-682, 2001

57. Spiegel D, Bloom JR, Kraemer $\mathrm{HC}$, et al: Effect of psychosocial treatment on survival of patients with metastatic breast cancer. Lancet 2:888891, 1989

58. Goodwin PJ, Leszcz $M$, Ennis $M$, et al: The effect of group psychosocial support on survival in metastatic breast cancer. N Engl J Med 345:17191726, 2001

59. Spiegel D, Butler LD, Giese-Davis J, et al: Effects of supportive-expressive group therapy on survival of patients with metastatic breast cancer: A randomized prospective trial. Cancer 110:11301138, 2007

60. Edwards AG, Hulbert-Williams N, Neal RD: Psychological interventions for women with metastatic breast cancer. Cochrane Database Syst Rev 3:CD004253, 2008
61. Boesen $\mathrm{EH}$, Johansen C: Impact of psychotherapy on cancer survival: Time to move on? Curr Opin Oncol 20:372-377, 2008

62. Daniels J, Kissane DW: Psychosocial interventions for cancer patients. Curr Opin Oncol 20: 367-371, 2008

63. Temel JS, Greer JA, Muzikansky A, et al: Early palliative care for patients with metastatic nonsmall-cell lung cancer. N Engl J Med 363:733-742, 2010

64. USA Today: Census reports more unmarried couples living together. http://usatoday30.usatoday.com/ news/nation/census/2008-07-28-cohabitationcensus N.htm

65 United States Census Bureau: Living Arrangements of Persons 15 years Old and Over by Race and Age: 2010. http://www.census.gov/compendia/ statab/2012/tables/12s0058.pdf

66. Duffy SA, Ronis DL, McLean S, et al: Pretreatment health behaviors predict survival among patients with head and neck squamous cell carcinoma. J Clin Oncol 27:1969-1975, 2009

67. Browman GP, Wong G, Hodson I, et al: Influence of cigarette smoking on the efficacy of radiation therapy in head and neck cancer. N Engl J Med 328:159-163, 1993

68. Gritz ER, Demark-Wahnefried W: Health behaviors influence cancer survival. J Clin Oncol 27 1930-1932, 2009

69. Miller PM, Day TA, Ravenel MC: Clinical implications of continued alcohol consumption after diagnosis of upper aerodigestive tract cancer. Alcohol Alcohol 41:140-142, 2006

70. Ang KK, Harris J, Wheeler R, et al: Human papillomavirus and survival of patients with oropharyngeal cancer. N Engl J Med 363:24-35, 2010

71. Lindström M: Social capital, economic conditions, marital status and daily smoking: A populationbased study. Public Health 124:71-77, 2010

72. Power C, Rodgers B, Hope S: Heavy alcohol consumption and marital status: Disentangling the relationship in a national study of young adults. Addiction 94:1477-1487, 1999 